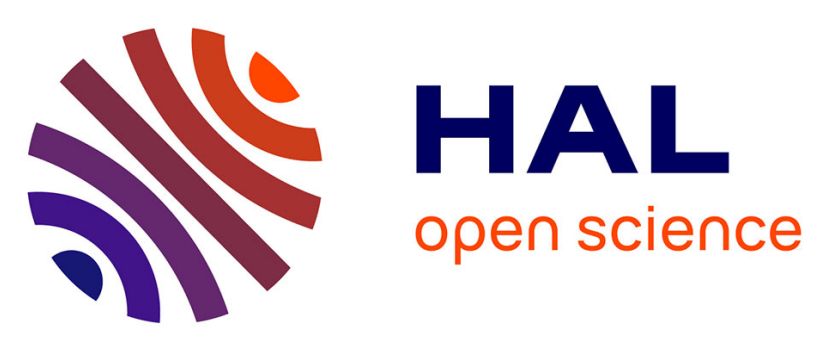

\title{
Lipid content and response to insulin are not invariably linked in human muscle cells
}

Céline Aguer, Jacques Mercier, Magali Kitzmann

\section{To cite this version:}

Céline Aguer, Jacques Mercier, Magali Kitzmann. Lipid content and response to insulin are not invariably linked in human muscle cells. Molecular and Cellular Endocrinology, 2009, 315 (1-2), pp.225. 10.1016/j.mce.2009.10.017 . hal-00547662

\section{HAL Id: hal-00547662 \\ https://hal.science/hal-00547662}

Submitted on 17 Dec 2010

HAL is a multi-disciplinary open access archive for the deposit and dissemination of scientific research documents, whether they are published or not. The documents may come from teaching and research institutions in France or abroad, or from public or private research centers.
L'archive ouverte pluridisciplinaire HAL, est destinée au dépôt et à la diffusion de documents scientifiques de niveau recherche, publiés ou non, émanant des établissements d'enseignement et de recherche français ou étrangers, des laboratoires publics ou privés. 


\section{Accepted Manuscript}

Title: Lipid content and response to insulin are not invariably linked in human muscle cells

Authors: Céline Aguer, Jacques Mercier, Magali Kitzmann

PII: $\quad$ S0303-7207(09)00564-4

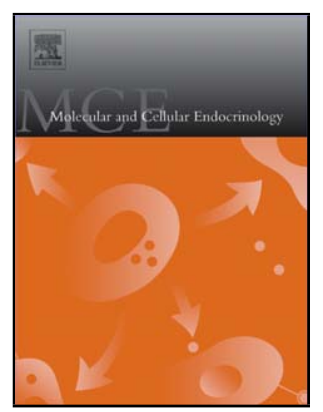

DOI: doi:10.1016/j.mce.2009.10.017

Reference: MCE 7363

To appear in: Molecular and Cellular Endocrinology

Received date:

18-6-2009

Revised date:

$30-10-2009$

Accepted date:

30-10-2009

Please cite this article as: Aguer, C., Mercier, J., Kitzmann, M., Lipid content and response to insulin are not invariably linked in human muscle cells, Molecular and Cellular Endocrinology (2008), doi:10.1016/j.mce.2009.10.017

This is a PDF file of an unedited manuscript that has been accepted for publication. As a service to our customers we are providing this early version of the manuscript. The manuscript will undergo copyediting, typesetting, and review of the resulting proof before it is published in its final form. Please note that during the production process errors may be discovered which could affect the content, and all legal disclaimers that apply to the journal pertain. 


\section{Lipid content and response to insulin are not invariably linked in human muscle cells}

Céline Aguer ${ }^{1,2}$, Jacques Mercier ${ }^{1,2,3}$ and Magali Kitzmann ${ }^{1,2, *}$

${ }^{1}$ INSERM, ESPRI25 Muscle et pathologies, Montpellier, F-34295, France

${ }^{2}$ Université MONTPELLIER1, EA4202 Muscle et pathologies, Montpellier, F-34060, France

${ }^{3}$ CHU Montpellier, Hôpital Lapeyronie, Service de Physiologie Clinique, Montpellier, F-34295, France

*Corresponding author: Magali KITZMANN: magali.kitzmann@inserm.fr, Phone: 334674152 25, Fax: 33467415231

Address: INSERM, ESPRI25 Muscle et pathologies, Hôpital A. de Villeneuve, Bâtiment Crastes de Paulet, Avenue du Doyen G. Giraud, Montpellier Cedex 5, F-34295, France 


\begin{abstract}
In type 2 diabetes, a strong correlation between intramyocellular lipid accumulation and insulin resistance exists but whether intramyocellular accumulation is a cause or a consequence of insulin resistance is not clear. Lipid accumulation and response to insulin were evaluated in primary human myotubes derived from non-diabetic subjects and type 2 diabetic patients. Myotubes derived from type 2 diabetic patients had a defective response to insulin without showing a significant increase in lipid accumulation compared to myotubes derived from nondiabetic subjects. In myotubes derived from non-diabetic subjects, response to insulin stimulation (Akt phosphorylation) was abrogated and lipid content was increased after palmitate treatment. However, chronic exposure to insulin or inhibition of mitochondrial activity by antimycin led to independent changes of lipid content and response to insulin in myotubes derived from nondiabetic subjects. Altogether these results suggest that lipid accumulation and response to insulin are not invariably linked.
\end{abstract}

Key words: skeletal muscle, insulin signaling, fatty acid, lipid accumulation, human, myotubes 


\section{Introduction}

Obesity-associated insulin resistance is a major risk factor for type 2 diabetes and cardiovascular disease. Skeletal muscle accounts for the bulk of insulin-mediated glucose disposal and thus is important for systemic energy metabolism. Intramyocellular lipid (IMCL) accumulation in skeletal muscle is abnormally high in obesity, type 2 diabetes and other metabolic conditions. Elevated IMCL stores in the obese and/or type 2 diabetic patient seem to be secondary to a structural imbalance between plasma free fatty-acid (FFA) availability, fatty acid (FA) storage and oxidation [1,2]. Numerous studies have reported a strong relationship between IMCL content and insulin resistance [2-4]. Lipid infusion or high fat diet applied on healthy persons induced an increase in both plasma FFA level and IMCL content in relation with a significant decrease in insulin sensitivity [5,6]. Moreover, addition of FFA on myotubes established from rodent cell lines induced insulin resistance in relation with IMCL accumulation [7-9]. However, most of the investigations have been correlative in nature and IMCL accumulation within skeletal muscle may not be invariably linked to insulin resistance since endurance-trained athletes have an enhanced storage of IMCL despite their high insulin sensitivity $[10,11]$

Gene-environment interaction can be viewed as a departure from an otherwise expected additivity of genetic and environmental factors on a given outcome measure. Human satellite cells have been shown to display the majority of the defects previously described for type 2 diabetic muscle in vivo including defective insulin signaling pathway [12-14], reduced insulinstimulated glycogen synthase (GS), glucose transport activities [14,15] and reduced lipid oxidation [16,17]. In this context, cell culture of primary human myotubes offers an excellent model to evaluate the causality of the relation between IMCL accumulation and response to insulin by measuring inherited intrinsic defects under standardized conditions.

In the present study, we used primary human muscle cell cultures grown from satellite cells taken from non-diabetic subjects and type 2 diabetic patients, to determine the gene-environment interaction between IMCL accumulation and response to insulin. 


\section{Materials and Methods}

\section{In vivo human experimental procedures \\ Subjects}

A total of 13 volunteers ( 5 male subjects with no family history of type 2 diabetes and 8 male type 2 diabetic patients) participated to this study. Subjects were matched on age and physical activity measured by VOORRIPS index [18]. The experimental protocol was approved by the local ethic committee (03/10/GESE, Montpellier, France). Informed and written consent was obtained from all subjects after explanation of the protocol.

\section{In vitro experimental procedures}

Primary human muscle cell culture: process of purification

A skeletal muscle biopsy of the vastus lateralis was performed according to the percutaneous Bergström technique after local anesthesia (xylocaine) [19,20]. $50 \mathrm{mg}$ of muscle biopsy were scissor-minced and tissue explants were plated into collagen coated dishes as previously described [21]. After 10 to 15 days, cells migrated out of explants. Cells were purified using an immunomagnetic bead based sorting system [22] with MACS microbeads directly linked to an antibody to NCAM (CD56) [21]. Cultures were maintained in a growth medium composed of (DMEM, 10\% FBS and 1\% Ultroser G) and when CD56+ cells reached confluence, medium was changed (growth medium minus Ultroser $\mathrm{G}$ ) and the differentiation process occurred until fusion and terminal differentiation into contractile myotubes ( 8 days).

\section{Myotubes treatments}

Treatments performed on myotubes are detailed in the figure legends and were realized in triplicate for each of the 13 independent cultures. The following reagents: L-Glutamine, DMEM, palmitate and antimycin were purchased from Sigma-Aldrich (Saint Quentin Fallavier, France), FBS from Hyclone (Brebières, France), insulin from Lilly (Suresnes, France). Palmitate was dissolved in chloroform $(0.6 \mathrm{~mol} / \mathrm{l})$, diluted to $0.6 \mathrm{mmol} / \mathrm{l}$ in DMEM containing $10 \%$ of FBS and added to the myotubes. Untreated myotubes were incubated in DMEM containing $10 \%$ FBS and $0.1 \%$ chloroform without palmitate.

\section{IMCL content}

Lipid content in myotubes was visualized by oil red O (Sigma-Aldrich, Saint Quentin Fallavier, France) staining. Myotubes were firstly washed with PBS. Oil red O staining was carried for one hour followed by 2 or 3 washes with distilled water. In order to quantify IMCL content in myotubes, oil red $\mathrm{O}$ was extracted using isopropanol for $10 \mathrm{~min} .1 \mathrm{ml}$ of sample was transferred into spectrophotometer cuvets. The absorbance value was measured using a spectrophotometer set at $490 \mathrm{~nm}$ [23] and blanked to untreated cells.

\section{Western Blots}

Cell lysates were quantified (Biorad protein assay, Biorad, Paris, France), $30 \mu \mathrm{g}$ of total proteins were separated by SDS-PAGE and then transferred to nitro-cellulose membranes (Schleicher and Schuell Bioscience, Dassel, Germany). Western blots were realized as previously described [24]. Following primary antibodies were used: polyclonal anti-phospho-Glycogen Synthase (Ser641) (Cell Signaling Technology, Ozyme, Saint-Quentin-en-Yvelines, France) diluted 1/200, monoclonal anti-phospho-Akt (Ser473) (587F11)(Cell Signaling Technology, Ozyme, SaintQuentin-en-Yvelines, France) diluted 1/200, polyclonal anti-Akt (Cell Signaling Technology, 
Ozyme, Saint-Quentin-en-Yvelines, France) diluted 1/200, monoclonal anti-troponin T and monoclonal anti- $\alpha$-tubulin (Sigma-Aldrich, Saint Quentin Fallavier, France) diluted 1/500. The secondary antibodies were anti-rabbit and anti-mouse antibodies coupled to horseradish peroxydase (Amersham Bioscience, Orsay, France). Proteins were visualized using an enhanced luminescent reagent (Santa Cruz Biotechnology, Tebu-Bio, Le Perray en Yvelines, France), and exposed to autoradiograph film (Amersham Bioscience, Orsay, France). Expressions of $\alpha$-tubulin and Troponin $\mathrm{T}$ were used as a loading charge control and a marker of myotube differentiation, respectively. Expression of proteins was quantified by density analysis using ImageJ Launcher Software.

\section{Statistical analyses}

Data are presented as mean \pm SEM. Statistical analyses were performed using Statview 5.0. Student's t test for unpaired and paired comparison or a two-way ANOVA were used to assess statistical differences. $\mathrm{p}<0.05$ was considered to be significant. 


\section{Results}

Following insulin stimulation, activation of Akt is known to phosphorylate and inactivate Glycogen Synthase Kinase-3 (GSK-3), resulting in the dephosphorylation of Glycogen Synthase (GS) that controls the rate of glycogen metabolism. Akt activation is known to trigger the translocation of Glucose Transporter 4 (GLUT4) to plasma membrane in response to insulin. Thus, increased Akt phosphorylation and decreased GS phosphorylation in response to insulin stimulation are positive markers of GLUT4 translocation and glycogen synthesis.

Figure 1A shows representative western blots of Ser473 phosphorylation of Akt and of Ser641 phosphorylation of GS, with or without insulin stimulation, performed on myotubes derived from non-diabetic subjects (ND) and type 2 diabetic patients (T2D). ND myotubes show a response to insulin as attested by the significant increase in Ser473-Akt (Fig. 1B) and the significant decrease in Ser641-GS (Fig. 1B) phosphorylation levels after insulin stimulation. In contrast, phosphorylation of these proteins was not significantly modified after insulin stimulation in T2D myotubes (Fig.1B). This difference in the response to insulin between ND and T2D myotubes was not the result of a difference in the loading charge as quantification of Ser473-Akt and of Ser641-GS was normalized to $\alpha$-tubulin expression. Troponin $\mathrm{T}$ is only expressed in differentiated muscle cells and was used to show that satellite cells (ND or T2D) derived from muscle biopsies were able to form myotubes. As shown on Figure 1A, Ser473-Akt level was increased in some myotubes derived from T2D patients. We have thus monitored P-Akt to Akt ratio in ND and T2D myotubes in basal state and after insulin stimulation (Fig. 1C). ND myotubes show a response to insulin as attested by the significant increase in P-Akt to Akt ratio (Fig. 1D). In contrast, P-Akt to Akt ratio was neither significantly modified after insulin stimulation in T2D myotubes (Fig.1D) nor significantly different in the basal state between ND and T2D myotubes (Fig. 1D). IMCL content was not significantly different between ND and T2D myotubes neither after palmitate treatment $(\mathrm{p}>0.05)$ nor after insulin and palmitate treatment $(\mathrm{p}>0.05)$ (Fig. 1E).

The importance of FFA in the development of type 2 diabetes is well reported (for review [25]). Studies on muscle cell lines showed that palmitate (saturated FFA) treatment induced lipid accumulation and insulin resistance [7-9]. Figure 2A shows representative western blots of Ser473 phosphorylation of Akt and of Ser641 phosphorylation of GS, with or without insulin stimulation, performed on myotubes derived from two different non-diabetic subjects (ND1 and ND2) treated or not by palmitate. Response to insulin stimulation at the level of Ser473 Akt phosphorylation was abrogated after palmitate treatment (Fig. 2B) whereas response to insulin at the level of Ser641 GS phosphorylation was unchanged. Quantification of IMCL after palmitate treatment for 16 hours in $\mathrm{C}$ myotubes is presented in Figure 2C. Palmitate treatment induced a significant increase in IMCL content $(\mathrm{p}<0.05)$.

Chronic insulin treatment is known to decrease insulin-stimulated PI3K activity and glucose uptake in mouse cell lines (C2C12) [26]. We have confirmed that chronic insulin exposure (64 hours) abrogated the response to insulin in ND myotubes, at the level of Ser473 Akt and Ser641 GS phosphorylation (Fig. 3A and 3B). To know if the induction of insulin resistance in these cells was associated with an increase in IMCL content, we have measured the change in IMCL content after chronic insulin exposure before palmitate treatment (Fig. 3C). No significant modification in the content of IMCL was observed in myotubes derived from non-diabetic subjects after chronic insulin exposure.

A current hypothesis to explain the increase in IMCL accumulation in insulin resistant state is a reduced lipid oxidative capacity commonly associated with mitochondrial dysfunction $[27,28]$. In 
order to evaluate whether mitochondrial activity inhibition could decrease insulin sensitivity by increasing IMCL content in ND myotubes, cells were exposed to an inhibitor of oxidative phosphorylation (antimycin) before palmitate treatment. Mitochondrial activity inhibition by antimycin did not alter the response to insulin at the level of Ser473 Akt and Ser641 GS phosphorylation (Fig. 4A and 4B). However, after mitochondrial inhibition, IMCL accumulation was significantly increased in ND myotubes (Fig. 4C) $(\mathrm{p}<0.05)$. 


\section{DISCUSSION}

The cause of muscle insulin resistance is not yet clearly identified. Several studies have demonstrated that IMCL content was inversely related to the degree of insulin sensitivity [2$4,29]$, such that increased insulin resistance was associated with increased IMCL accumulation. However, the proposed relationship between IMCL content and insulin resistance does not appear to be functional, as endurance-trained athletes have an elevated IMCL content despite being highly insulin sensitive $[1,10]$. The aim of the present study was to evaluate the causality of the relation between IMCL accumulation and response to insulin in a cell culture model.

\section{T2D myotubes are insulin resistant without increased lipid accumulation}

Several studies have demonstrated that insulin resistance was conserved in myotubes derived from type 2 diabetic patients $[12,14,15]$. In our study, we have shown that primary human skeletal muscle cells derived from type 2 diabetic patients preserved insulin resistance in vitro at the level of insulin-stimulated phosphorylation of Ser473 of Akt and dephosphorylation of Ser641 of GS. An increase in P-Akt in the basal situation was observed in T2D myotubes, however, this increase was also observed for the non-phosphorylated form of Akt leading to a normal P-AKT to Akt ratio in the basal state in T2D myotubes. Insulin resistance in T2D myotubes is thus characterized by a decreased insulin-stimulated Akt and GS activation. Surprisingly, T2D myotubes did not show a significant increase in lipid content after palmitate treatment compared to $\mathrm{C}$ myotubes. Our T2D myotubes are thus characterized by a defective response to insulin, not by an increased IMCL content.

\section{High FFA levels induces insulin resistance and IMCL accumulation in ND myotubes}

Palmitate is the most abundant systemic saturated fatty acid in the circulation and treatment of different cell types with palmitate has been found to inhibit protein kinase B (Akt) activity in response to insulin [30-32]. In our study, we found that palmitate treatment in myotubes derived from non-diabetic subjects abrogated insulin-stimulated Akt phosphorylation and induced IMCL accumulation. This result suggests that the increase in systemic FFA levels found in obese patients would be the cause of insulin resistance development and of increased IMCL accumulation. Nowadays, it is well documented that it is not IMTG pool per se, but rather the accumulation of lipid intermediates such as fatty acyl-CoA, ceramides and diacylglycerol DAG, which might suppress insulin signaling (for a review see [33]). Ceramide generation is sufficient to account for the inhibition of the insulin-stimulated pathway in $\mathrm{C} 2 \mathrm{C} 12$ cells pretreated with palmitate [9]. Treatment of human myotubes derived from healthy subjects and type 2 diabetic patients by $0.6 \mathrm{mmol} / 1$ of palmitic acid induced accumulation of TAG and phospholipids and to a lesser extend of cellular free palmitic acid and DAG [17]. Thus, we may suppose that increased lipid intermediates after palmitate exposure could be responsible for Akt inhibition in our cell culture model. However, in contrast to previous results showing that chronic palmitate exposure induced insulin resistance at the level of glycogen synthesis in myotubes derived from control subjects [34]; we did not observe a decrease in GS activation after palmitate exposure. 


\section{IMCL accumulation and insulin resistance are not invariably linked in ND myotubes}

Chronic exposure to high insulin concentration has been shown to induce insulin resistance in 3T3-L1 adipocytes [35,36] and in C2C12 myotubes [26,37]. We were able to reduce the response to insulin (Akt and GS) in myotubes derived from non-diabetic subjects by treating them with $1 \mu \mathrm{M}$ of insulin for 64 hours. Insulin resistance development was not followed by increased IMCL content in myotubes derived from non-diabetic subjects in a context of elevated FFA level. Thus, insulin resistance induced by chronic insulin treatment of myotubes derived from nondiabetic subjects does not lead to IMCL accumulation.-

Reduced lipid oxidative capacity in type 2 diabetes was commonly associated with mitochondrial dysfunction [27,28] and studies have demonstrated that mitochondrial phosphorylation was reduced in skeletal muscle of type 2 diabetic patients and insulin resistant offspring of type 2 diabetic parents [29,38]. Furthermore, this reduced mitochondrial function was conserved in primary human myotubes derived from type 2 diabetic patients [16,38]. To mimic the mitochondrial dysfunction in our cells derived from non-diabetic subjects, we exposed myotubes to an inhibitor of mitochondrial oxidative phosphorylation (antimycin). Mitochondrial activity inhibition before palmitate treatment induced a significant increase in IMCL content compared to palmitate treatment alone without inducing any change at the level of phosphorylation of Ser473 Akt or of Ser641 GS in response to insulin. Thus, by taking of mitochondrial function in myotubes derived from non-diabetic subjects, we were able to further increase IMCL accumulation but not to induce insulin resistance. This results is not surprising in light of recent results [39] showing that mitochondrial alterations do not precede the onset of insulin resistance. Mitochondrial inhibition is known to increase reactive oxygen species (ROS) production and palmitate was shown to induce insulin resistance through ROS produced by mitochondria in hepatocytes [40] and in skeletal muscle (for a review : [41]). Since antimycin addition, unlike palmitate treatment, did not abrogate insulin-stimulated Akt phosphorylation, we may suppose that in our cell culture model, ROS production after mitochondrial inhibition is limited.

Taken together these results show that IMCL accumulation and alteration in insulin signaling are not invariably linked in primary human myotubes. 


\section{ACKNOWLEDGMENTS}

This work was supported by grants from Association Française contre les Myopathies (AFM, MNM2 2005, $\mathrm{n}^{\circ} 11330$ ), Institut National de Santé et de la Recherche Médicale (INSERM, ESPRI25), Languedoc Roussillon Region, University of Montpellier 1 and CHU of Montpellier. We are grateful to the Centre de Recherche National Scientifique (CNRS) for its support to M. Kitzmann and to AFM and to Emo International for their fellowships to C. Aguer. 


\section{REFERENCES}

[1] van Loon, L.J. and Goodpaster, B.H. (2006) Increased intramuscular lipid storage in the insulin-resistant and endurance-trained state. Pflugers Arch 451, 606-16.

[2] Kriketos, A.D., Furler, S.M., Gan, S.K., Poynten, A.M., Chisholm, D.J. and Campbell, L.V. (2003) Multiple indexes of lipid availability are independently related to whole body insulin action in healthy humans. J Clin Endocrinol Metab 88, 793-8.

[3] Perseghin, G., Scifo, P., De Cobelli, F., Pagliato, E., Battezzati, A., Arcelloni, C., Vanzulli, A., Testolin, G., Pozza, G., Del Maschio, A. and Luzi, L. (1999) Intramyocellular triglyceride content is a determinant of in vivo insulin resistance in humans: a 1H-13C nuclear magnetic resonance spectroscopy assessment in offspring of type 2 diabetic parents. Diabetes 48, 1600-6.

[4] Pan, D.A., Lillioja, S., Kriketos, A.D., Milner, M.R., Baur, L.A., Bogardus, C., Jenkins, A.B. and Storlien, L.H. (1997) Skeletal muscle triglyceride levels are inversely related to insulin action. Diabetes 46, 983-8.

[5] Bachmann, O.P., Dahl, D.B., Brechtel, K., Machann, J., Haap, M., Maier, T., Loviscach, M., Stumvoll, M., Claussen, C.D., Schick, F., Haring, H.U. and Jacob, S. (2001) Effects of intravenous and dietary lipid challenge on intramyocellular lipid content and the relation with insulin sensitivity in humans. Diabetes 50, 2579-84.

[6] Boden, G., Lebed, B., Schatz, M., Homko, C. and Lemieux, S. (2001) Effects of acute changes of plasma free fatty acids on intramyocellular fat content and insulin resistance in healthy subjects. Diabetes 50, 1612-7.

[7] Pedrini, M.T., Kranebitter, M., Niederwanger, A., Kaser, S., Engl, J., Debbage, P., Huber, L.A. and Patsch, J.R. (2005) Human triglyceride-rich lipoproteins impair glucose metabolism and insulin signalling in L6 skeletal muscle cells independently of nonesterified fatty acid levels. Diabetologia 48, 756-66.

[8] Perdomo, G., Commerford, S.R., Richard, A.M., Adams, S.H., Corkey, B.E., O'Doherty, R.M. and Brown, N.F. (2004) Increased beta-oxidation in muscle cells enhances insulinstimulated glucose metabolism and protects against fatty acid-induced insulin resistance despite intramyocellular lipid accumulation. J Biol Chem 279, 27177-86.

[9] Schmitz-Peiffer, C., Craig, D.L. and Biden, T.J. (1999) Ceramide generation is sufficient to account for the inhibition of the insulin-stimulated $\mathrm{PKB}$ pathway in $\mathrm{C} 2 \mathrm{C} 12$ skeletal muscle cells pretreated with palmitate. J Biol Chem 274, 24202-10.

[10] Goodpaster, B.H., He, J., Watkins, S. and Kelley, D.E. (2001) Skeletal muscle lipid content and insulin resistance: evidence for a paradox in endurance-trained athletes. J Clin Endocrinol Metab 86, 5755-61.

[11] van Loon, L.J. (2004) Intramyocellular triacylglycerol as a substrate source during exercise. Proc Nutr Soc 63, 301-7.

[12] Bouzakri, K., Roques, M., Gual, P., Espinosa, S., Guebre-Egziabher, F., Riou, J.P., Laville, M., Le Marchand-Brustel, Y., Tanti, J.F. and Vidal, H. (2003) Reduced activation of phosphatidylinositol-3 kinase and increased serine 636 phosphorylation of insulin receptor substrate-1 in primary culture of skeletal muscle cells from patients with type 2 diabetes. Diabetes 52, 1319-25.

[13] Jackson, S., Bagstaff, S.M., Lynn, S., Yeaman, S.J., Turnbull, D.M. and Walker, M. (2000) Decreased insulin responsiveness of glucose uptake in cultured human skeletal muscle cells from insulin-resistant nondiabetic relatives of type 2 diabetic families. Diabetes 49, 1169-77. 
[14] Nikoulina, S.E., Ciaraldi, T.P., Carter, L., Mudaliar, S., Park, K.S. and Henry, R.R. (2001) Impaired muscle glycogen synthase in type 2 diabetes is associated with diminished phosphatidylinositol 3-kinase activation. J Clin Endocrinol Metab 86, 4307-14.

[15] Gaster, M., Petersen, I., Hojlund, K., Poulsen, P. and Beck-Nielsen, H. (2002) The diabetic phenotype is conserved in myotubes established from diabetic subjects: evidence for primary defects in glucose transport and glycogen synthase activity. Diabetes 51, 9217.

[16] Gaster, M., Rustan, A.C., Aas, V. and Beck-Nielsen, H. (2004) Reduced lipid oxidation in skeletal muscle from type 2 diabetic subjects may be of genetic origin: evidence from cultured myotubes. Diabetes 53, 542-8.

[17] Gaster, M., Rustan, A.C. and Beck-Nielsen, H. (2005) Differential utilization of saturated palmitate and unsaturated oleate: evidence from cultured myotubes. Diabetes 54, 648-56.

[18] Voorrips, L.E., Ravelli, A.C., Dongelmans, P.C., Deurenberg, P. and Van Staveren, W.A. (1991) A physical activity questionnaire for the elderly. Med Sci Sports Exerc 23, 974-9.

[19] Thomas, C., Sirvent, P., Perrey, S., Raynaud, E. and Mercier, J. (2004) Relationships between maximal muscle oxidative capacity and blood lactate removal after supramaximal exercise and fatigue indexes in humans. J Appl Physiol 97, 2132-8.

[20] Thomas, C., Perrey, S., Lambert, K., Hugon, G., Mornet, D. and Mercier, J. (2005) Monocarboxylate transporters, blood lactate removal after supramaximal exercise, and fatigue indexes in humans. J Appl Physiol 98, 804-9.

[21] Kitzmann, M., Bonnieu, A., Duret, C., Vernus, B., Barro, M., Laoudj-Chenivesse, D., Verdi, J.M. and Carnac, G. (2006) Inhibition of Notch signaling induces myotube hypertrophy by recruiting a subpopulation of reserve cells. J Cell Physiol.

[22] Sinanan, A.C., Hunt, N.P. and Lewis, M.P. (2004) Human adult craniofacial musclederived cells: neural-cell adhesion-molecule (NCAM; CD56)-expressing cells appear to contain multipotential stem cells. Biotechnol Appl Biochem 40, 25-34.

[23] Gaster, M. and Beck-Nielsen, H. (2006) Triacylglycerol accumulation is not primarily affected in myotubes established from type 2 diabetic subjects. Biochim Biophys Acta.

[24] Kitzmann, M., Carnac, G., Vandromme, M., Primig, M., Lamb, N.J. and Fernandez, A. (1998) The muscle regulatory factors MyoD and myf-5 undergo distinct cell cyclespecific expression in muscle cells. J Cell Biol 142, 1447-59.

[25] Wilding, J.P. (2007) The importance of free fatty acids in the development of Type 2 diabetes. Diabet Med 24, 934-45.

[26] Kumar, N., Kaul, C.L., Ishrath, A. and Dey, C.S. (2004) Combination of metformin and thiazolidindiones restore insulin signalling in insulin-resistant cultured myotubes. Life Sci 74, 1877-88.

[27] Kelley, D.E., He, J., Menshikova, E.V. and Ritov, V.B. (2002) Dysfunction of mitochondria in human skeletal muscle in type 2 diabetes. Diabetes 51, 2944-50.

[28] Mogensen, M., Sahlin, K., Fernstrom, M., Glintborg, D., Vind, B.F., Beck-Nielsen, H. and Hojlund, K. (2007) Mitochondrial respiration is decreased in skeletal muscle of patients with type 2 diabetes. Diabetes 56, 1592-9.

[29] Petersen, K.F., Dufour, S., Befroy, D., Garcia, R. and Shulman, G.I. (2004) Impaired mitochondrial activity in the insulin-resistant offspring of patients with type 2 diabetes. $\mathrm{N}$ Engl J Med 350, 664-71.

[30] Soltys, C.L., Buchholz, L., Gandhi, M., Clanachan, A.S., Walsh, K. and Dyck, J.R. (2002) Phosphorylation of cardiac protein kinase B is regulated by palmitate. Am J Physiol Heart Circ Physiol 283, H1056-64. 
[31] Kausch, C., Staiger, H., Staiger, K., Krutzfeldt, J., Matthaei, S., Haring, H.U. and Stumvoll, M. (2003) Skeletal muscle cells from insulin-resistant (non-diabetic) individuals are susceptible to insulin desensitization by palmitate. Horm Metab Res 35, 570-6.

[32] Chavez, J.A. and Summers, S.A. (2003) Characterizing the effects of saturated fatty acids on insulin signaling and ceramide and diacylglycerol accumulation in 3T3-L1 adipocytes and C2C12 myotubes. Arch Biochem Biophys 419, 101-9.

[33] Timmers, S., Schrauwen, P. and de Vogel, J. (2008) Muscular diacylglycerol metabolism and insulin resistance. Physiol Behav 94, 242-51.

[34] Just, M., Faergeman, N.J., Knudsen, J., Beck-Nielsen, H. and Gaster, M. (2006) Longchain Acyl-CoA is not primarily increased in myotubes established from type 2 diabetic subjects. Biochim Biophys Acta 1762, 666-72.

[35] Ricort, J.M., Tanti, J.F., Van Obberghen, E. and Le Marchand-Brustel, Y. (1995) Alterations in insulin signalling pathway induced by prolonged insulin treatment of 3T3L1 adipocytes. Diabetologia 38, 1148-56.

[36] Thomson, M.J., Williams, M.G. and Frost, S.C. (1997) Development of insulin resistance in 3T3-L1 adipocytes. J Biol Chem 272, 7759-64.

[37] Ju, J.S., Gitcho, M.A., Casmaer, C.A., Patil, P.B., Han, D.G., Spencer, S.A. and Fisher, J.S. (2007) Potentiation of insulin-stimulated glucose transport by the AMP-activated protein kinase. Am J Physiol Cell Physiol 292, C564-72.

[38] Ortenblad, N., Mogensen, M., Petersen, I., Hojlund, K., Levin, K., Sahlin, K., BeckNielsen, H. and Gaster, M. (2005) Reduced insulin-mediated citrate synthase activity in cultured skeletal muscle cells from patients with type 2 diabetes: evidence for an intrinsic oxidative enzyme defect. Biochim Biophys Acta 1741, 206-14.

[39] Bonnard, C., Durand, A., Peyrol, S., Chanseaume, E., Chauvin, M.A., Morio, B., Vidal, H. and Rieusset, J. (2008) Mitochondrial dysfunction results from oxidative stress in the skeletal muscle of diet-induced insulin-resistant mice. J Clin Invest 118, 789-800.

[40] Nakamura, S., Takamura, T., Matsuzawa-Nagata, N., Takayama, H., Misu, H., Noda, H., Nabemoto, S., Kurita, S., Ota, T., Ando, H., Miyamoto, K. and Kaneko, S. (2009) Palmitate induces insulin resistance in H4IIEC3 hepatocytes through reactive oxygen species produced by mitochondria. J Biol Chem 284, 14809-18.

[41] Silveira, L.R., Fiamoncini, J., Hirabara, S.M., Procopio, J., Cambiaghi, T.D., Pinheiro, C.H., Lopes, L.R. and Curi, R. (2008) Updating the effects of fatty acids on skeletal muscle. J Cell Physiol 217, 1-12. 


\section{FIGURES AND LEGENDS}

FIG. 1. Decreased insulin response is conserved in T2D myotubes. Representative western blot analysis of Ser641 GS and Ser473 Akt phosphorylation in myotubes established from nondiabetic subjects (ND) and type 2 diabetic patients (T2D) with (+) or without (-) insulin stimulation ( $1 \mu \mathrm{M}$ for $10 \mathrm{~min})$. Cell extracts were then prepared and immunoblotted for phosphoGS (Ser641) and phospho-Akt (Ser473), expression. Troponin T and $\alpha$-Tubulin were used as markers of myotube differentiation and loading charge control, respectively. B. Quantification by density analysis of Ser641 GS and Ser473 Akt phosphorylation in myotubes with (+) or without (-) insulin stimulation ( $1 \mu \mathrm{M}$ for $10 \mathrm{~min})$, from 5 cultures established from non-diabetic subjects (ND, white bars) and 8 cultures established from type 2 diabetic patients (T2D, black bars). Data are presented normalized to $\alpha$-Tubulin protein expression. Data are shown as mean \pm $\mathrm{SE}$ and represent an average of 1-6 independent experiments for each culture. ${ }^{*} \mathrm{p}<0.05$. C. Western blot analysis of serine 473 phosphorylation of Akt (P-Akt) in myotubes established from ND subjects and T2D patients with (+) or without (-) insulin stimulation (100 nM for $10 \mathrm{~min})$. D. Quantification by density analysis of P-Akt in myotubes with (+) or without (-) insulin stimulation $(100 \mathrm{nmol} / \mathrm{l}$ for $10 \mathrm{~min})$, from $\mathrm{ND}(\mathrm{n}=4)$ and T2D ob $(\mathrm{n}=4)$ cultures. Data are presented normalized to Akt protein expression. Data are shown as mean \pm SEM. $* \mathrm{p}<0.05$, significant effect of treatment. E. IMCL content in myotubes derived from non-diabetic subjects $(\mathrm{ND}, \mathrm{n}=5)$ and type 2 diabetic patients $(\mathrm{T} 2 \mathrm{D}, \mathrm{n}=8)$. Myotubes were exposed to palmitate $(0.6$ $\mathrm{mM})$ and/or insulin $(1 \mu \mathrm{M})$ for 16 hours. IMCL content was determined spectrometrically, as described in materials and methods. Data are shown as mean \pm SEM. Each point was assayed in triplicate for each of the 13 independent cell cultures.

FIG. 2 Decreased insulin response and increased IMCL content after palmitate treatment of ND myotubes. A. Representative western blot analysis of Ser641 GS and Ser473 Akt phosphorylation in myotubes established from two non-diabetic subjects (ND1 and ND2). Myotubes with (+) or without (-) palmitate treatment $(0.6 \mathrm{mM}$ for 16 hours) were then stimulated $(+)$ or not (-) by insulin $(1 \mu \mathrm{M}$ for $10 \mathrm{~min})$. Cell extracts were then prepared and immunoblotted for phospho-GS (Ser641) and phospho-Akt (Ser473) expression. Troponin T and $\alpha$-Tubulin were used as markers of myotube differentiation and loading charge control, respectively. B. Quantification by density analysis of insulin-stimulated Ser641 GS and Ser473 Akt phosphorylation in myotubes with (+) or without (-) palmitate stimulation $(0.6 \mathrm{mM}$ for 16 hours), from 4 cultures established from nondiabetic subjects. Data are presented normalized to $\alpha$-Tubulin protein expression. Data are shown as mean \pm SEM. ${ }^{*} p<0.05$. C. IMCL content is plotted in ND myotubes $(n=5)$ with $(+)$ or without (-) palmitate treatment $(0.6 \mathrm{mM}$ for 16 hours $)$ as the increment after palmitate treatment normalized to baseline condition (untreated cells). IMCL content was determined spectrometrically, as described in materials and methods. Data are shown as mean \pm SEM. Each point was assayed in triplicate for each of the 5 independent cell cultures. ${ }^{*} \mathrm{p}<0.05$.

FIG. 3. Decreased insulin response but normal IMCL accumulation after chronic insulin treatment of ND myotubes. A. Representative western blot analysis of Ser641 GS and Ser473 Akt phosphorylation in myotubes established from two ND subjects (ND1 and ND2). Myotubes were chronically stimulated (+) or not (-) by insulin $(1 \mu \mathrm{M}$ for 64 hours) followed (+) or not (-) by insulin stimulation $(1 \mu \mathrm{M}$ for $10 \mathrm{~min})$. Cell extracts were then prepared and immunoblotted for phospho-GS (Ser641) and phospho-Akt (Ser473) expression. Troponin T and $\alpha$-Tubulin were used as a marker of myotube differentiation and loading charge control, respectively. B. 
Quantification by density analysis of insulin-stimulated Ser641 GS and Ser473 Akt phosphorylation in myotubes with (+) or without (-) chronic insulin stimulation $(1 \mu \mathrm{M}$ for 64 hours), from 4 cultures established from non-diabetic subjects. Data are presented normalized to $\alpha$-Tubulin protein expression. Data are shown as mean \pm SEM. ${ }^{*} \mathrm{p}<0.05$. C. IMCL content in ND myotubes $(\mathrm{n}=4)$ with $(+)$ or without $(-)$ chronic insulin stimulation $(1 \mu \mathrm{M}$ for 48 hours $)$ followed by palmitate treatment $(0.6 \mathrm{mM}$ for 16 hours $)$. IMCL content is plotted as the change after chronic insulin stimulation normalized to palmitate treatment alone. IMCL content was determined spectrometrically, as described in materials and methods. Data are shown as mean \pm SEM. Each point was assayed in triplicate for each of the 4 independent cell cultures.

FIG. 4. Normal insulin response but increased IMCL accumulation after antimycin treatment of ND myotubes A. Representative western blot analysis of Ser641 GS and Ser473 Akt phosphorylation in myotubes established from two non-diabetic subjects (ND1 and ND2). Myotubes with (+) or without (-) antimycin treatment $(1 \mu \mathrm{g} / \mathrm{ml}$ for 16.5 hours $)$ were then stimulated (+) or not (-) by insulin $(1 \mu \mathrm{M}$ for $10 \mathrm{~min})$. Cell extracts were then prepared and immunoblotted for phospho-GS (Ser641) and phospho-Akt (Ser473) expression. Troponin T and $\alpha$-Tubulin were used as markers of myotube differentiation and loading charge control, respectively. B. Quantification by density analysis of insulin-stimulated Ser641 GS and Ser473 Akt phosphorylation in myotubes with (+) or without (-) antimycin stimulation $(1 \mu \mathrm{g} / \mathrm{ml}$ for 16.5 hours), from 4 cultures established from non-diabetic subjects. Data are presented normalized to $\alpha$-Tubulin protein expression. Data are shown as mean \pm SEM. ${ }^{*} \mathrm{p}<0.05$. C. IMCL content in ND myotubes $(\mathrm{n}=5)$ with $(+)$ or without $(-)$ mitochondrial activity inhibition by antimycin $(1 \mu \mathrm{g} / \mathrm{ml}$ for $30 \mathrm{~min})$ followed (+) by palmitate treatment $(0.6 \mathrm{mM}$ for 16 hours $)$. IMCL content is plotted as the increment after mitochondrial inhibition normalized to palmitate treatment alone. IMCL content was determined spectrometrically, as described in materials and methods. Data are shown as mean \pm SEM. Each point was assayed in triplicate for each of the 5 independent cell cultures. $* \mathrm{p}<0.05$. 
Figure

Figure 1

A

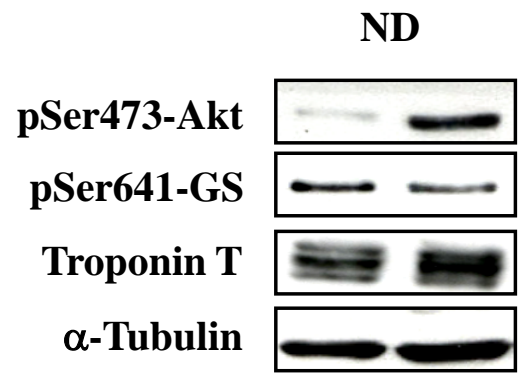

T2D

Insulin

B

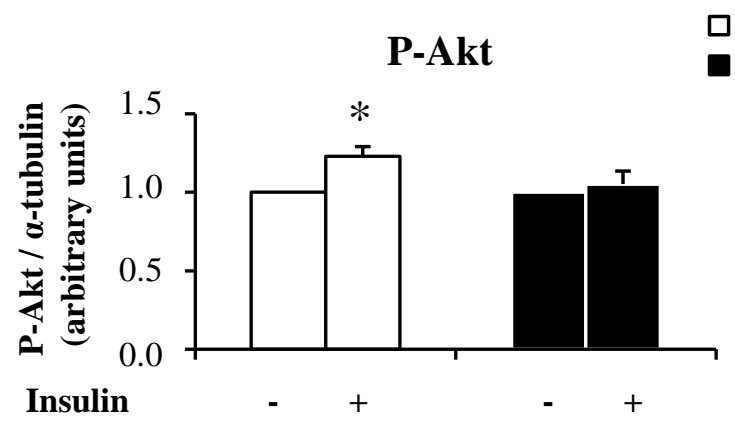

ㅁ ND
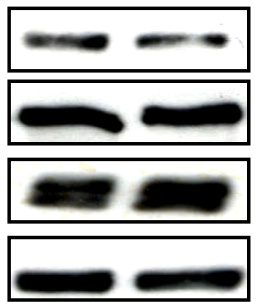

C

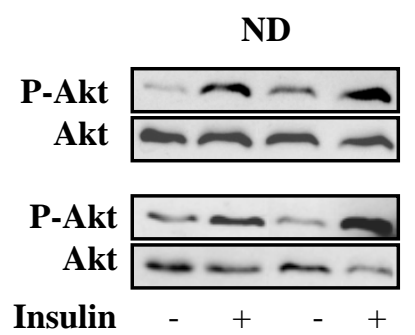

T2D

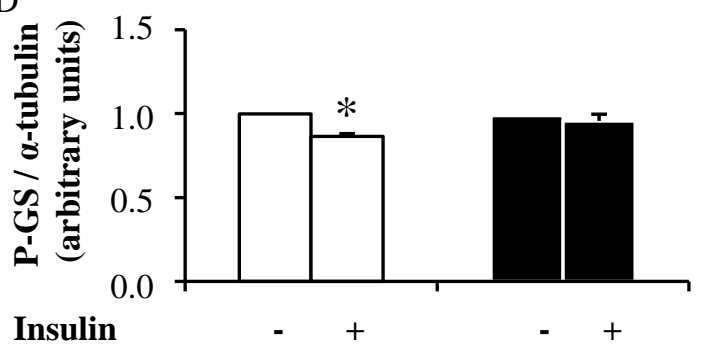

D

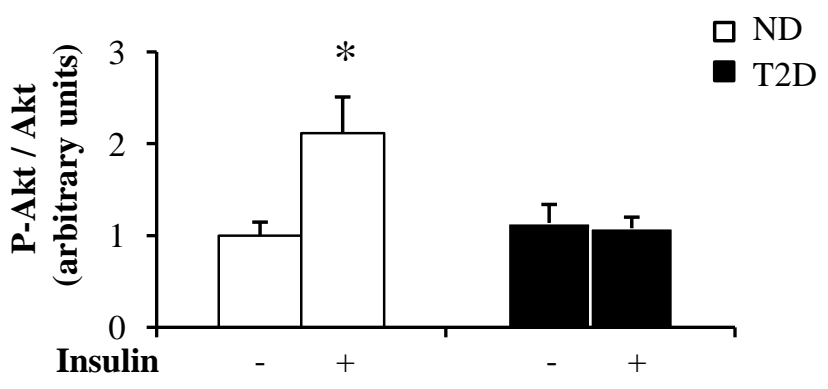

E

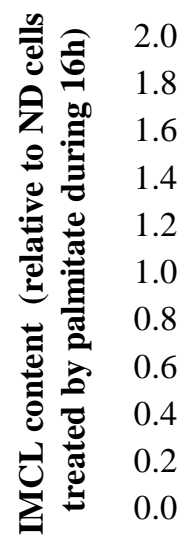

$\square$ ND

- T2D

Palmitate Insulin

Aguer et al 
Figure 2

A

ND1

ND2

pSer473-Akt
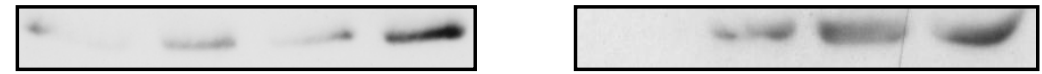

pSer641-GS

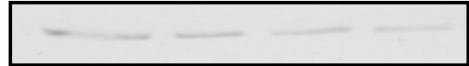

Troponin T
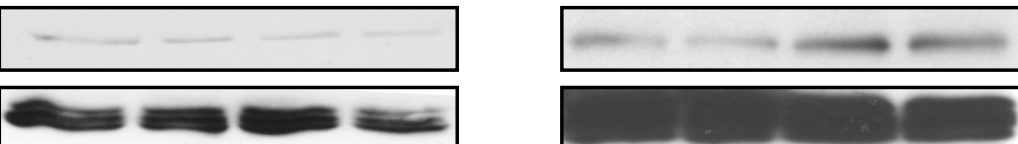

$\alpha$-Tubulin

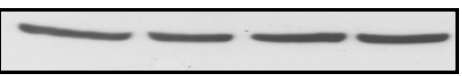

Insulin

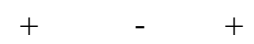

Palmitate

B

\section{P-Akt}
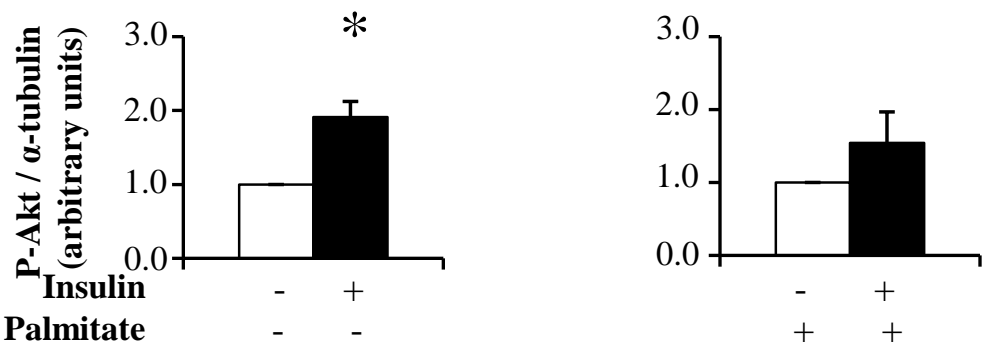

P-GS

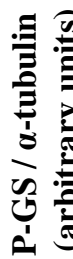

Insulin

Palmitate

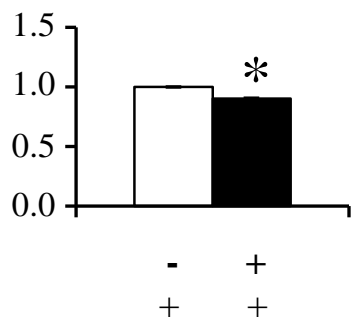

C

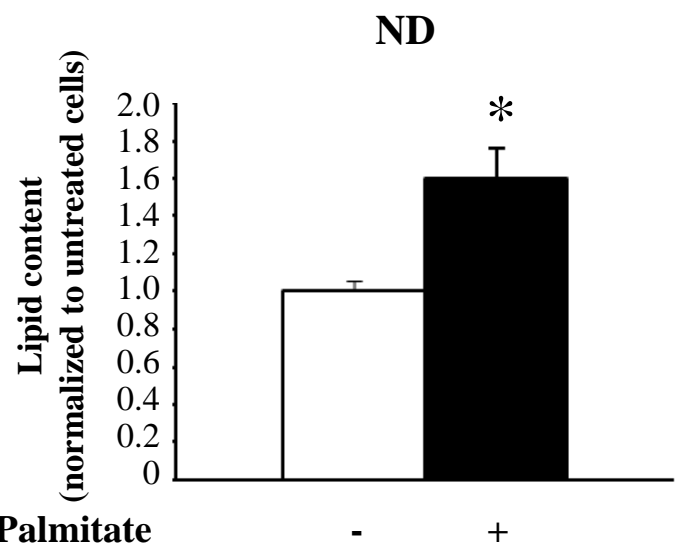


Figure 3

A

ND1

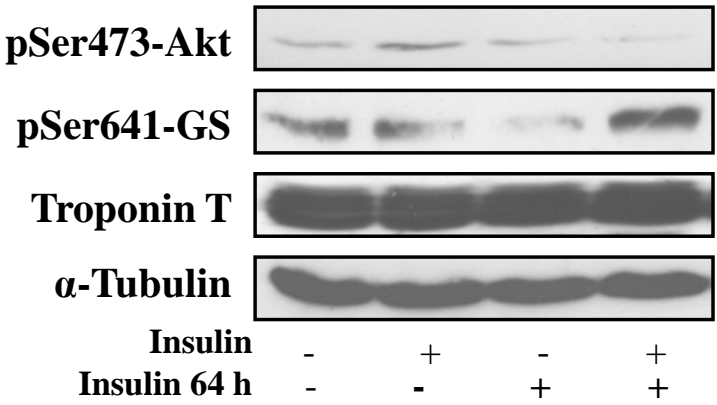

ND2
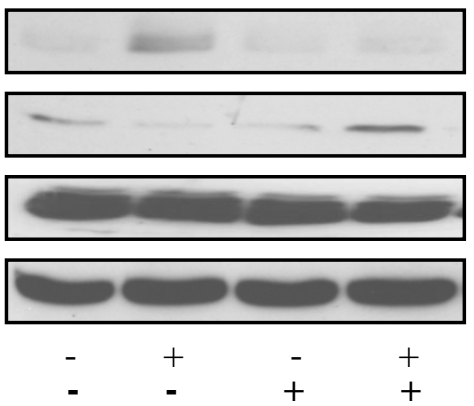

B

\section{P-Akt}
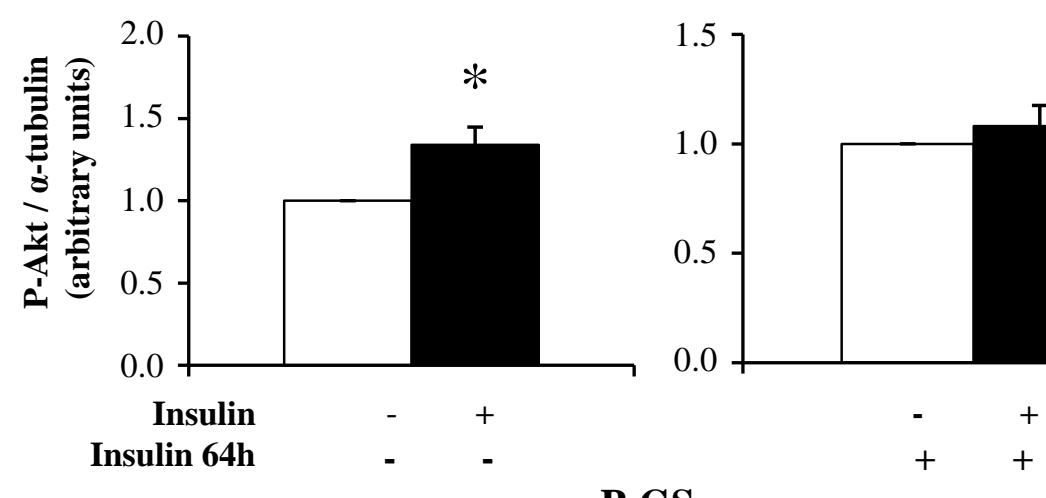

Insulin 64h

P-GS
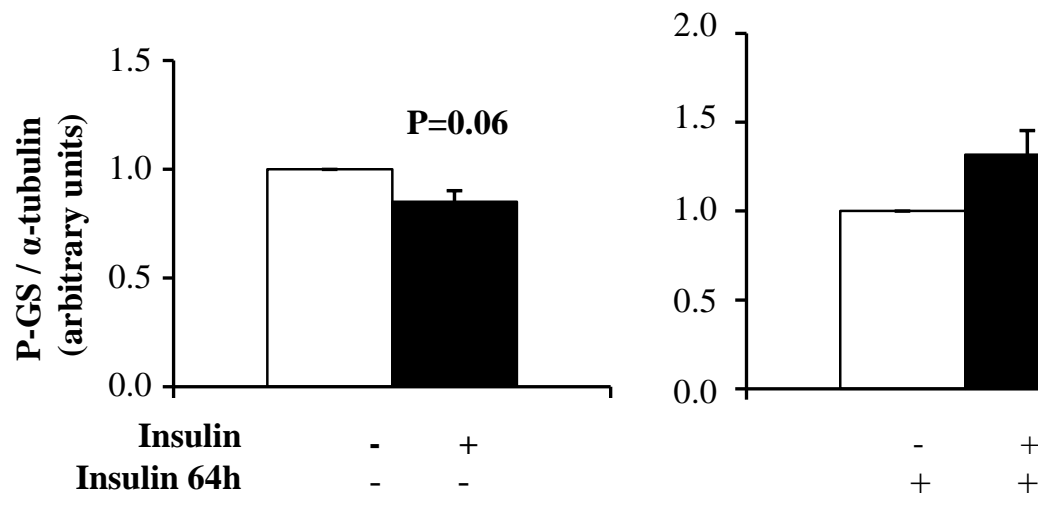

C

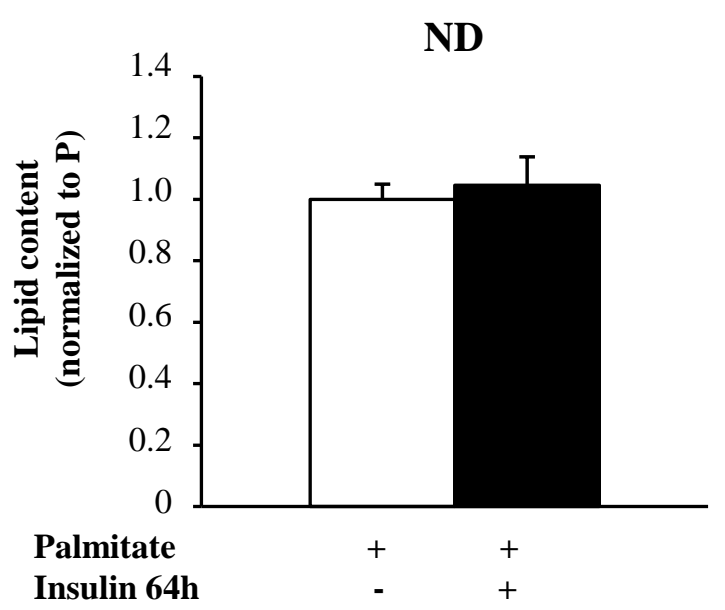


Figure 4

A

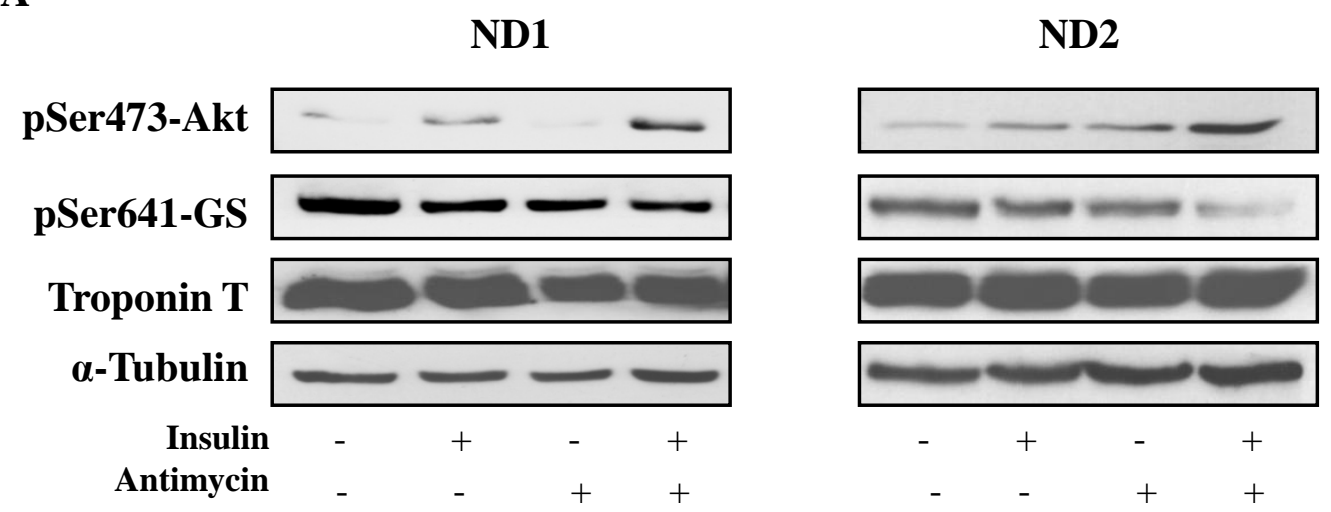

B

P-Akt
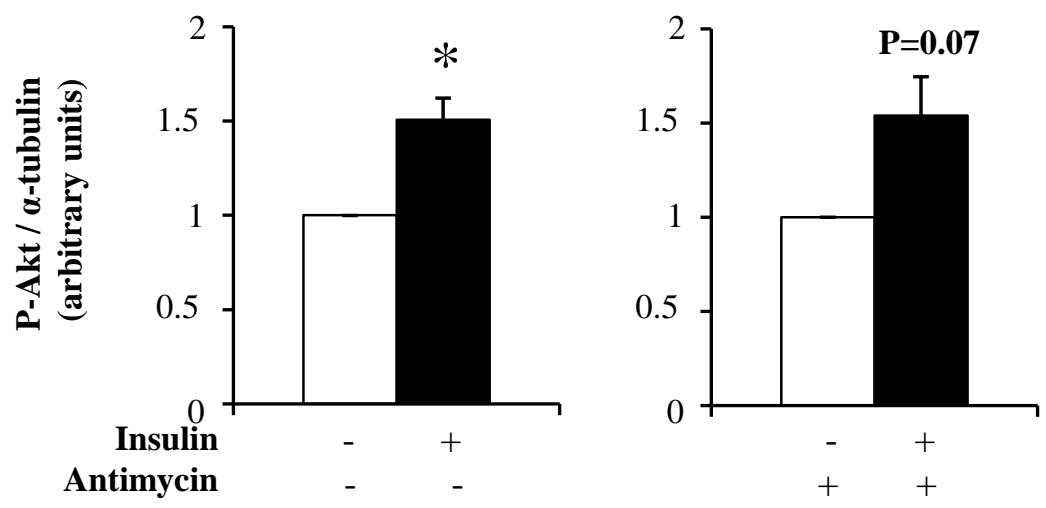

P-GS
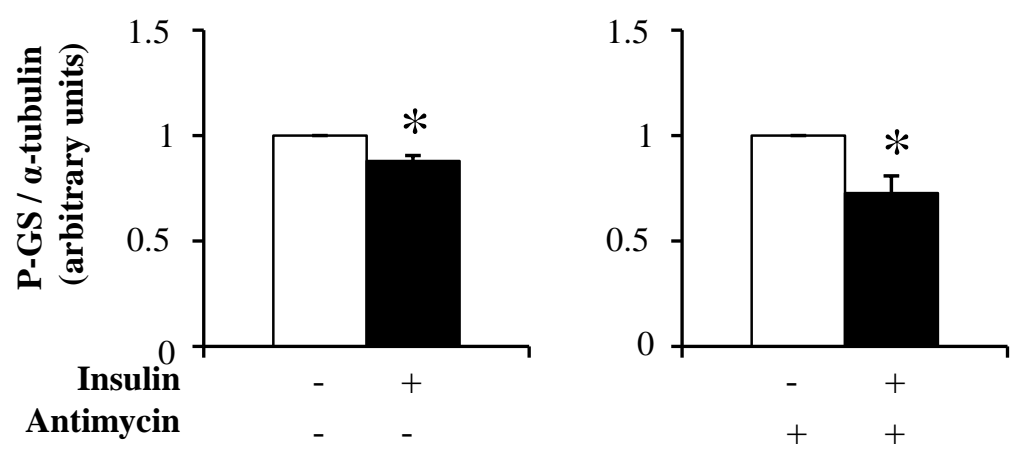

C

ND

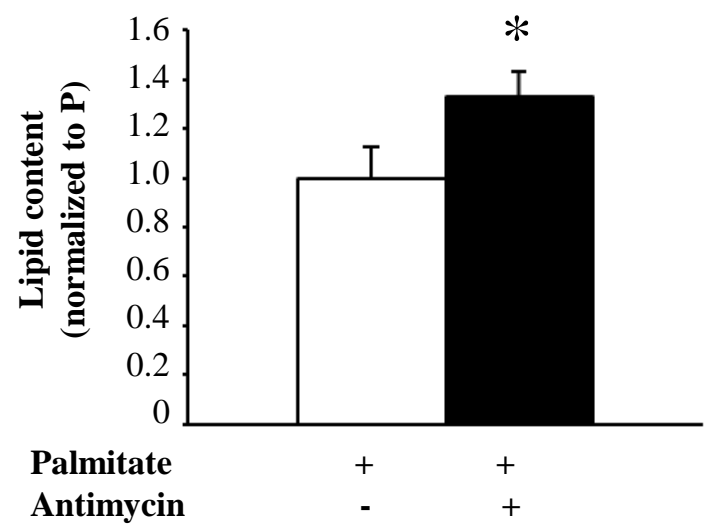

